\title{
The Bilateral Relationship Between Tourism and Dengue Occurrence: Evidence From Aruba
}

\author{
Marck Oduber \\ Meteorological Department of Aruba, Sabana Berde, Aruba \\ Jorge Ridderstaat \\ Central Bank of Aruba, Oranjestad, Aruba \\ Pim Martens \\ Maastricht University, Maastricht, the Netherlands
}

\begin{abstract}
This study estimates the bilateral effects between seasonal patterns of dengue incidences and the recurring fluctuations of both stay-over tourism and cruise tourism. Seasonal patterns were first isolated from the series using the Census X-12 decomposition method, after which the analysis included panel data unit root testing, panel data regression, and Mahalanobis distance calculation. The results show that cruise tourism increases dengue cases in Aruba, while dengue cases themselves had no influence on the number of stay-over and cruise visitors in Aruba. The study hints for an economical duality in cruise tourism in Aruba: (1) On one hand, cruise tourists who arrive at the harbor contribute to the economy of Aruba due to their spending activities; and (2) On the other hand, cruise tourists can induce costs by increasing the risk of spreading dengue. The Mahalanobis distance showed that the sensitivity of dengue cases to cruise tourism was the strongest during February, April-July, October, and November.
\end{abstract}

Keywords: seasonality, dengue, tourism demand, panel data, small island, Aruba

\section{Introduction}

Dengue is the most important viral vector-borne disease and an increasing problem globally (Gratz \& Knudsen, 1996). The disease is caused by four related yet distinct types of viruses transmitted by aedes mosquitoes, which are very sensitive to environmental settings (Gubler \& Kuno, 1997). The mosquito bite can induce dengue fever, dengue hemorrhagic fever, and dengue hemorrhagic shock, which can all be deadly (Chakraborty, 2008). The economic impact of dengue fever or dengue hemorrhagic fever can be enormous, placing significant burdens on affected communities. This impact varies and can include: loss of life; medical expenditures, among others, for hospitalization of patients; loss in productivity of the affected workforce; strain on health care services due to sudden, high demand during an epidemic; considerable expenditures for large-scale emergency control actions; and loss of tourism as a result of negative publicity (Meltzer, Rigau-Perez, Clark, Reiter, \& Gubler, 1998). It is estimated that almost 50 million people travel annually from

Marck Oduber, director, Meteorological Department of Aruba. Email: marck.oduber@meteo.aw.

Jorge Ridderstaat, manager of the Research Department, Central Bank of Aruba.

Pim Martens, scientific director of the International Centre for Integrated Assessment and Sustainable Development (ICIS), Maastricht University. 
develop countries to tropical and third world countries, where morbidity to tropical countries carries a high risk (Stienlauf, Segal, Sidi, \& Schwartz, 2005). As more countries develop their tourism industry, it induces significant impacts on natural resources, consumption patterns, pollution, and social systems. The need for sustainable or responsible planning and management is necessary for the industry to survive as a whole. Several studies show that dengue can influence tourism (e.g., Cobelens, Groen, Osterhaus, Leentvaar-Kuipers, Wertheim-van Dillen, \& Kager, 2002; Wichmann, Muhlberger, \& Jelinek, 2003; Schwartz, Weld, Wilder-Smith, von Sonnenburg, Keystone, Kain, ..., \& GeoSentinel Surveillance Network, 2008). For example, Cobelens et al. (2002) studied the incidence of dengue virus infections in a group of Dutch travelers to Asia, and observed that dengue infections were frequent in travelers to endemic areas in Asia. Schwartz et al. (2008) studied seasonality and annual trends for dengue cases among returned travelers. They showed that dengue cases exhibit region-specific peaks, where travel-related dengue had annual oscillations, and recommended that pre-travel advice should include information on relative risks of dengue infection according to season. Most of these studies looked at travelers acquiring the virus at a destination or the risk of infection and returning with the virus back home, but to our knowledge, there is a certain lack of studies exploring how dengue influences seasonal patterns of international tourism demand to Small Island Developing States. Principals of sustainability refer to the environmental, economic, and socio-cultural aspects of tourism development, where an appropriate balance must be made among these three dimensions to guarantee its long-term sustainability (United Nations Environment Programme [UNEP], 2005). This stresses the case for a better understanding of the elements of tourism flow in small island economies. Croes (2006) indicated that many small islands use tourism development as a growth strategy for greater economic and development performance. Thacker, Acevedo, and Perrelli (2012) showed that the positive contribution from specializing in tourism has helped to offset the negative impact of being a small island economy, and according to the authors, tourism has been a significant provider to lower output volatility in many countries.

The purpose of this paper is to address the bilateral relationship between the seasonal time series of tourism demand and dengue incidence for a small island state. This involves analyzing, for the small island state of Aruba, the seasonal variations from tourism demand, namely, cruise tourism and stay-over tourism, the seasonal variations incidences of dengue cases reported, and the seasonal variations of climatic variables, namely, surface temperature, average maximum and minimum temperatures, rainfall, relative humidity, cloud incidences, and wind speed. The methodology involves the decomposition of time series on cruise tourism, stay-over tourism, dengue incidence, and several climate elements using Census X-12 decomposition procedure, and subsequent application of panel unit root test, panel regression, and the Mahalanobis distance calculation. The observed studies presented earlier, although suggestive, were often inadequate to provide how dengue influences seasonal patterns of tourism demand in small island destinations. Therefore, there is a case for better understanding the drivers of tourism demand in small island economies. Our study accesses Aruba as the case of interest. Yin (2009) indicated possible contributions of individual case studies to scientific generalizations through replication, where the mode is analytical generalization. The idea is then to expand and generalize theories, and not to enumerate frequencies (statistical generalizations). Authors such as Eisenhardt and Graebner (2007) stated that building theory from case studies is a research strategy that requires as minimum one case to create theoretical constructs, propositions, and/or mid-range theory from case-based empirical evidence.

The rest of this paper is organized as follows. Section 2 discusses previous literature on dengue and its economic and tourism impact. Section 3 discusses climate conditions in Aruba, and the island's tourism 
industry. In Section 4, the data and the applied methodology are reviewed. In Section 5, results and discussion are presented, whereas Section 6 concludes and offers policy implications and lines for future research.

\section{A Review of the Literature}

\section{Dengue}

Dengue is the most important viral vector-borne disease and an increasing problem globally (Gratz \& Knudsen, 1996). In 1944, Dr. Albert Sabin isolated and identified the dengue virus (Chakraborty, 2008). The disease is caused by one of the four related yet distinct viruses named dengue virus 1 (DEN-1), dengue virus 2 (DEN-2), dengue virus 3 (DEN-3), and dengue virus 4 (DEN-4) (Gubler \& Kuno, 1997), and transmission depends on vulnerable populations living in urban environments where sanitation is poor and rainfall run-off water accumulates. Dengue viruses are spread from viremic to susceptible human beings (host) by the mosquito (vector) aedes aegypti and aedes albopictus (Kovats, Campbell-Lendrum, Reid, \& Martens, 2000). The mosquitoes attain the virus when they feed on a viremic person. The mosquito can transmit dengue if it immediately bites another host or after 8-12 days of viral replication in its salivary glands, the so-called extrinsic incubation period (Chakraborty, 2008). The mosquito stays infected for the remainder of its 15- to 65-day lifespan. Vertical transmission of dengue virus in mosquitoes has been noted, whereby therefore infected mosquitoes can pass the virus on to their young. The female mosquito lays its eggs on walls of both artificial and natural water containers. The eggs of aedes mosquitoes are able to withstand long periods of desiccation, as long as one year (Chakraborty, 2008). Once a host gets infected, it has an intrinsic incubation period of 3-14 days. After the incubation, a 5- to 7-day acute febrile (fever) illness ensues. Healing usually is complete within 7-10 days. When a host gets infected with one type of dengue virus, it provides lifelong protection from re-infection with that same serotype, but only partial and short-lived protection from infection with other dengue serotypes (Chakraborty, 2008). Persons who have had prior infection with one or more dengue serotypes can develop a more severe form of dengue, namely, dengue hemorrhagic fever or dengue shock syndrome. Two main factors that regulate aedes aegypti populations are, namely, climate and available breeding sites. Climatic parameters, such as humidity and temperature, have an influence on dengue transmission, for example, during high humidity periods, mosquito survivals are longer and can increase the chance of transmission (Gubler \& Kuno, 1997). Higher temperatures can shorten the extrinsic incubation period and produce smaller females that are forced to make more blood meals to obtain the amount of protein needed for egg production, therefore increasing the number of individuals infected by a single female (Gubler \& Kuno, 1997). High ambient temperatures can even have a more powerful effect on the vector mosquito population than increased moisture accompanying a rainy season (Halstead, 2008). Wind can also induce an influence on the aedes aegypti. The aedes aegypti has a flight range from $2.5 \mathrm{~km}$ per day in an open environment to a few hundreds to less than $25 \mathrm{~m}$ in an urban environment (Halstead, 2008).

\section{Economic Impact of Dengue}

Dengue fever/dengue hemorrhagic fever can have enormous economic consequences, placing significant burdens on affected communities. The impact can include: loss of life; medical expenditures for sick patients; loss in productivity due to workers on sick leave; strain on health care services due to sudden, high demand during an epidemic; expenditures for emergency control actions; and loss of tourism as a result of negative publicity (Meltzer et al., 1998). Costs estimates related to dengue in the Caribbean region include losses of 
US $\$ 8$ million in Puerto Rico and US\$103 million in Cuba (Halstead, 2008). The cost of the illness includes both direct (medical costs) and indirect costs (value of the lost time entailing lost wages, etc.) (Suaya, Shepard, \& Beatty, 2007). Costs related to intervention can be considered research and development costs, household insecticide expenditure, and government vector control programs. Separate from the immediate costs, vector-borne diseases such as dengue can also have other costs such as mortality, long-term morbidity, adverse influences on education, economic growth, reduced per capita income, and reduced foreign direct investments (Mavalankar, Puwar, Murtola, \& Vasan, 2009). A method for estimating costs associated with dengue illnesses of all degrees of severity (mortality and morbidity) employs disability-adjusted life years (DALY's) (Halstead, 2008). In Puerto Rico, between 1984 and 1994, the economic burden due to dengue was estimated at 658 DALY's per year per million inhabitants. This value was found to be as important as that for tuberculosis and sexually transmitted diseases (except for HIV/AIDS).

\section{Tourism and Dengue Connection}

From anecdotal and published materials, it is inferred that tourism can be influenced by natural events (seismological and meteorological events), socio-political instabilities, and epidemic outbreaks. In the age of globalization, enhanced mobility and labor flow related to international travel acts as an important factor for the spreading of infectious diseases. All tourism destinations are somewhat sensitive to climate. Tourist destinations can be either positively or negatively influenced by climate variability that induces climate anomalies that influence a tourist's comfort, safety, and the products that attract tourists or deter tourists, such as infectious diseases (Scott, Lemieux, \& Malone, 2011). A downturn in tourism demand, during epidemics, can cause a negative effect on the local economy (Yoshikawa \& Kusriastuti, 2013). Vector-borne diseases such as dengue and malaria can induce epidemics, which could influence tourism demand. Some authors hypothesized that take-off benefits associated with the decision to eliminate vector-borne diseases such as malaria may manifest positively in foreign direct investments, including tourism growth (Sabot, Cohen, Hsiang, Kahn, Basu, Tang, ..., \& Feachem, 2010). Except for the local burden induced by a vector-borne disease on a tourist destination, the disease can influence the tourist itself. A study done by Wichmann et al. (2003) shows that health care providers in European travel clinics are more and more confronted with dengue. They noted that infections were acquired in all endemic regions of the globe, with the highest frequencies in Southeast Asia. Wichmann et al. (2003) indicated that at the root of the emergence of dengue are changes in human demography and behavior and also increased air travel of humans who are incubating the virus and thus providing an ideal mechanism for transporting pathogens among population centers of the tropics. Therefore, travelers have the potential to not only acquire a dengue infection, but also to extend new and potentially more virulent strains to diverse areas of the world. Schwartz et al. (2008) examined seasonality and annual trends for dengue cases among returned travelers and noticed that dengue cases indicated region specific peaks for Southeast Asia, South-central Asia, South, and the Caribbean. As noted by Wichmann, Hongsiriwon, Bowonwatanuwong, Chotivanich, Sukthana, and Pukrittayakamee (2004), despite all terrorism threats and economic crises in recent years, in 2002, the number of international tourist arrivals exceeded 700 million for the first time in history. This increase, together with the increasing frequency of dengue in the tropics, is responsible for increased chances that health care providers will be confronted with imported dengue virus infection. Secondly, travelers might introduce more virulent strains into areas with mild cases and introduce dengue virus into non-endemic areas where the mosquito vector as aedes aegypti is present. 
Over the last one hundred-plus years, tourism has become the world's largest business, surpassing defense, manufacturing, oil, and agriculture industries and is a significant contributor to economies worldwide, where international tourist arrivals and the number of destinations increased (Lundberg, Krishnamoorthy, \& Stavenga, 1995; Goeldner \& Ritchie, 2009; Scott et al., 2011) (United Nations World Tourism Organization [UNWTO]). To keep up-to-date with the rapidly growing tourism phenomenon, destinations need sufficient forecasts of tourism demand for planning and managerial decisions (Goh, 2012). Vanegas and Croes (2000) indicated that there needs to be at first an adequate insight into the factors that influence tourism demand. Then, a detailed understanding of the patterns of development of tourism demand over time is necessary. Many studies on the determinants of tourism demand have been concentrated around economic factors (e.g., income and price) (Goh, 2012). According to Mavalankar et al. (2009), the quantification of the impact of various epidemics on tourism revenues is still inadequately addressed in peer-reviewed literature. Reported dengue cases can act as a deterrent for a tourist when selecting a tourist destination. In a study done on malaria, another vector-borne disease, it was reported that many persons cancelled their trips to Northern KwaZulu-Natal in the 1999/2000-malaria season. The high percentage of cancellations was due to the epidemic and extensive media coverage (Maartens, Sharp, Curtis, Mthembu, \& Hatting, 2007). A survey conducted by Maartens et al. (2007) found that tourism operators believed that malaria risk has a major impact on the foreign tourist market. Viral diseases such as SARS also show an effect on tourism through the reduction of inflow of foreign tourists, the reduction of tourist spending due to shorter stays, and reduction in premium visitors (Rossi \& Walker, 2005).

\section{Case Study}

\section{Climate Conditions of Aruba}

The island of Aruba is a Dutch island in the tropics and has a tropical steppe, semiarid hot climate. The wind blows for more than $95 \%$ of the time from the northeast and the southeast direction over Aruba, at an average speed of $7.3 \mathrm{~m} \mathrm{~s}^{-1}$ at 10-meter distance (1981-2010). Minimum wind speed is observed in October and November, and maximum wind speed is observed from May to July (Departamento Meteorologico Aruba, 2014). Aruba's average temperature is $27.9^{\circ}$ Celsius while varying during the year from $19.0^{\circ}$ Celsius to $36.5^{\circ}$ Celsius. The coldest months are January and February and the hottest ones are August and September. On average (1981-2010), Aruba receives $471.1 \mathrm{~mm}$ of rain. The wettest months are from October to December, and the driest months are from March to May. The potential for thunderstorms in Aruba is low, as compared to the rest of the tropics. Aruba has, on average, only 17.9 days per year where a thunderstorm passes over the observation site. The average relative humidity is $77.4 \%$, and the average cloud coverage in Aruba is $47.3 \%$ (Departamento Meteorologico Aruba, 2014).

\section{The Tourism Industry of Aruba}

Aruba has some 50 plus years of experience with the tourism industry. Starting from 1959, the island built its first 100-room hotel, modeled after similar ones in Florida and Puerto Rico (Cole \& Razak, 2009). However, the tourism industry played only a small role in the overall economic development of the island, given the dominant position of an oil refinery, the Lago Oil \& Transport Company, Ltd. (Vanegas \& Croes, 2000). This situation changed drastically in 1985, when the oil refinery closed its doors, considerably shocking the Aruban economy. At that time, the refinery contributed to about $25 \%$ of Aruba's gross domestic product (GDP), and directly and indirectly employed $30 \%-40 \%$ of Aruba's population (Ridderstaat, 2007). 
This unfavorable situation forced the government to start searching for a new source of economic activity. Experts showed that the most obvious way to increase income and foreign exchange receipts was to expand the tourism industry. Therefore, new hotels, shopping malls, and other commercial buildings were initiated. The number of hotel rooms more than tripled from 1986 to 2011. The majority of visitors came by airplane, and the number of aircraft landings almost doubled from 1986 to 2011 (Ridderstaat, Oduber, Croes, Nijkamp, \& Martens, 2014). The numbers of stay-over visitors, cruise passengers, and tourism receipts grew substantially from 1986 to 2011.

The United States tourist represents the main market for Aruba, accounting, on average, for roughly $63.5 \%$ of all stay-over visitors between 1981 and 2011. Most of these American tourists come from particularly the Northeastern part of the United States (Ridderstaat et al., 2014).

\section{Data and Methodology}

The basis for this study is the conceptual scheme depicted in Figure 1, where seasonal factors of cruise tourism and stay-over tourism are set against those of dengue cases. Climate plays a mediating role between dengue and tourism, as it can affect both. Ridderstaat et al. (2014) showed that climate is a significant push and pull factor influencing tourism demand. While other studies such as Pham, Doan, Phan, and Minh (2011) showed that climate acts as a main determinant of dengue fever. These studies are hinting for the mediating role of climate in dengue and tourism. According to Matzarakis (2006), the most relevant meteorological parameters for tourism include air temperature, air humidity, wind speed, wind direction, cloud coverage, sunshine duration, or radiations fluxes, rain and precipitation, snow coverage, and water temperature. According to Gubler and Kuno (1997), the most relevant meteorological parameters for dengue variability include air temperature, air humidity, and rainfall. For the purpose of this research, we use five weather fundamentals (cloud coverage, relative humidity, rainfall, temperature, and wind). The variable temperature was further sub-divided into average maximum and minimum temperatures and average temperature, as was proposed by other authors such as Wongkoon, M. U. Jaroensutasinee, and K. R. Jaroensutasinee (2011) and Gharbi, Quenel, Gustave, Cassadou, Ruche, Girdary, and Marrama (2011).

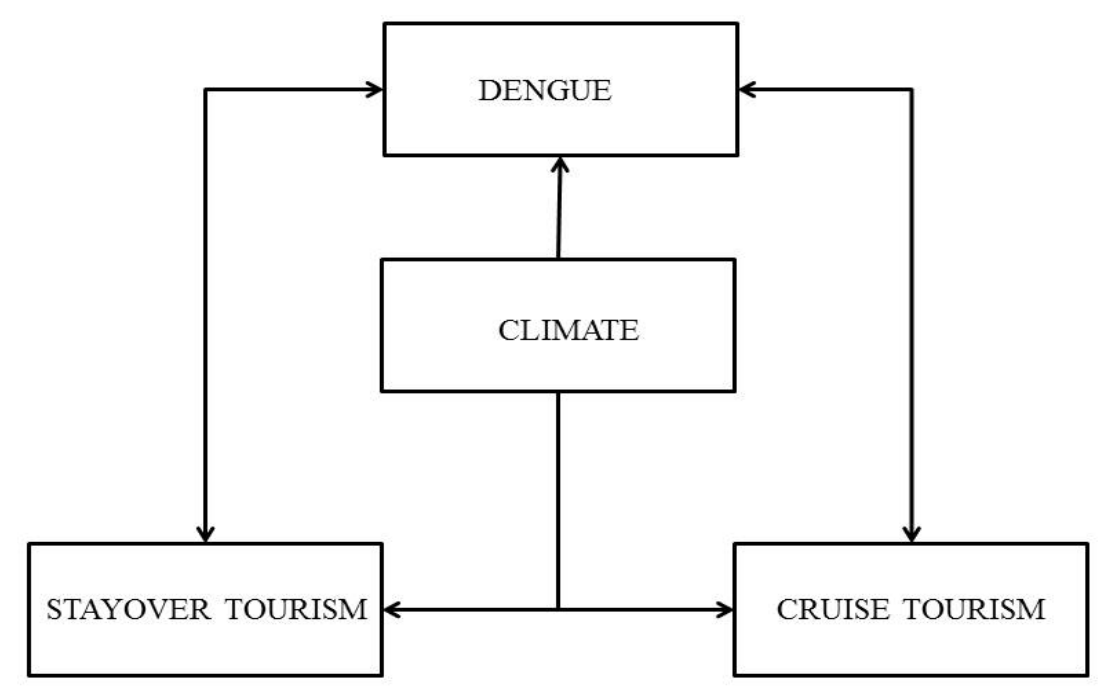

Figure 1. Conceptual framework of the relationship among dengue, tourism demand, and climate. 
The variables used in this study are shown in Table 1. Dengue cases for Aruba (AUA_DENGUE) are proxied by suspected dengue cases and are available for the years of 1999-2011 from the Department of Public Health. This is due to the limited amount of laboratory verified years. Furthermore, laboratory confirmed cases accounted for almost $90 \%$ of epidemiology suspected cases, when looking at years that had both laboratory confirmed cases and epidemiology suspected cases.

Table 1

Variables Used in the Analysis

\begin{tabular}{|l|l|l|l|}
\hline Variable type & Data description & Data period & Source \\
\hline Epidemiology & & & \\
\hline$A U A \_D E N G U E$ & Suspected dengue cases in Aruba & $1999-2011$ & Department of Public Health \\
\hline Tourism demand & & & \\
\hline CRUISE_TOUR & Tourism demand from cruises & $1999-2011$ & Central Bank of Aruba \\
\hline TOT_TOUR & Total tourism demand & $1999-2011$ & Central Bank of Aruba \\
\hline Weather & & & \\
\hline$A U A \_C L O U D$ & Cloud coverage in Aruba & & \\
\hline$A U A \_R H$ & Relative humidity in Aruba & $1999-2011$ & Meteorological Department of Aruba \\
\hline$A U A \_R A I N$ & Rainfall in Aruba & $1999-2011$ & Meteorological Department of Aruba \\
\hline$A U A \_T E M P$ & Average temperature in Aruba & $1999-2011$ & Meteorological Department of Aruba \\
\hline$A U A \_W I N D$ & Wind in Aruba & $1999-2011$ & Meteorological Department of Aruba \\
\hline$A U A \_M A X$ & Average maximum temperature in Aruba & $1999-2011$ & Meteorological Department of Aruba \\
\hline$A U A \_M I N$ & Average minimum temperature in Aruba & $1999-2011$ & Meteorological Department of Aruba \\
\hline
\end{tabular}

Tourism demand or flow is proxied separately by the total number of stay-over visitors (TOT_TOUR) and the total number of cruise visitors (CRUISE_TOUR) for the years of 1981-2011. These data are from the Central Bank of Aruba. Meteorological data for Aruba, consisting of relative humidity $\left(A U A \_R H\right)$, rainfall $\left(A U A_{-} R A I N\right)$, temperature $\left(A U A_{-} T E M P\right)$, maximum temperature $\left(A U A \_M A X\right)$, minimum temperature $\left(A U A_{-} M I N\right)$, wind $\left(A U A_{-} W I N D\right)$, and cloud coverage (AUA_CLOUD) are available for the years of 1981-2011, from the Meteorological Department of Aruba.

All series have been transformed by a Box-Cox power transformation, in order to make the distribution values more symmetrical and induce a variance-stabilizing effect (Wilks, 1995). Osborne (2010) showed that Box-Cox power transformations were superior to traditional transformations, such as square root, log, and inverse. The best transformation parameter was chosen using Hinkley's $d_{\lambda}$ statistic (Wilks, 1995).

Following Yu, Schwartz, and Walsh (2010), this study is based on the notion that time series can be decomposed into four different time-varying components (i.e., trend, cycle, incidental, and seasonal components). According to Yu et al. (2010), concentrating on seasonal components allows for the possibility to examine parameters, such as weather, dengue cases, and tourism demand in different seasons of the year. In addition, by using seasonal components, we can, for example, determine how similar the dengue cases are from those of tourism demand: The more similar they are, the more significant the impact of dengue case seasonality is on tourism demand seasonality, and vice versa.

Prior to applying the Census X-12 technique, the data were analyzed for the type of model (additive or multiplicative) they belong to. We apply the following regression, adapted from den Butter and Fase (1991), to assess the model type: 


$$
\left|Y-Y_{T}\right|=\alpha+\beta Y_{T}+\varepsilon_{t}
$$

where:

$Y=$ The original value of the time series;

$Y_{T}=$ The centralized moving average of $Y$ over a period of a year;

$\alpha, \beta=$ Coefficients;

$\varepsilon=$ Error.

If $Y$ and $Y_{T}$ are uncorrelated, meaning that the coefficient $\beta$ is not significantly different from zero, the model type is additive. If $\beta$ is significantly different from zero, the model is multiplicative.

After applying the Census X-12 methodology, all series were changed to standardized anomalies in order to work simultaneously with group of data that are associated but not strictly comparable (Hart \& Grumm, 2001). The standardized anomalies are dimensionless quantities. Standardized anomalies also remove the influence of location and spread from the data (Wilks, 1995).

One can test for the relative importance of seasonal (SF), trend-cyclic (TC), and irregular factors (IR) in the overall short-term volatility of the applied variables by doing the following regression borrowed from Ridderstaat et al. (2014):

$$
\Delta \text { Series }_{t}=\alpha_{1} \Delta \text { Series }_{E l, t}+\varepsilon_{1, t}
$$

where:

$\Delta=$ First difference;

$E l=$ Series' element $(\mathrm{TC}, \mathrm{SF}$, or IR);

$t=$ Time;

$\varepsilon=$ Residual.

The aim here is to determine the coefficient of determination (adjusted $R^{2}$ ) in order to assess the contribution of each of these three elements to the variability of the overall series. Given that the differencing occurs on a short-time range (i.e., month versus the next month), it is expected that the effects of the monthly differences would be likely dominated by a combination of both SF and IR elements.

Afterwards, the time series were transformed into balanced panel data type. Panel data consist of a time series for each cross-sectional member in the data set. Panel data have several advantages over purely cross-sections or purely time series (Asteriou \& Hall, 2007). Some of the advantages of panel data include: controling for individual heterogeneity, more informative data, more variability, more degrees of freedom, less collinearity, and studying dynamics of adjustments better (Baltagi, 2008).

In order to access the correct unit root test, a Mann-Kendall seasonal trend test was performed on the series. Mann-Kendall test is a statistical trend assessment broadly used in climatology (Mavromatis \& Stathis, 2011) and hydrology time-series studies (Yue \& Wang, 2004). The Mann-Kendall test is a non-parametric test and therefore does not require the data to be normally distributed. The Mann-Kendall test also has a low sensitivity to abrupt breaks due to inhomogeneous time series (Tabari, Somee, \& Zadeh, 2011). The Mann-Kendall test is based on the $S$-statistic (Onoz \& Bayazit, 2003). Each pair of observed values $x_{i}, x_{j},(i>j)$ of the random variable is examined to gauge whether $x_{i}>x_{j}$ or $x_{i}<x_{j}$. Let the number of the first type of pairs be $P$ and the number of the latter type of pairs be $M$, then $S$ is described as $S=P-M$. For $n>10$, the sampling distribution of $S$ is as follows, where $Z$ follows the standard normal distribution: 
and $\sigma_{s}=\sqrt{(n(n-1)(2 n+5)) / 18}$.

$$
Z= \begin{cases}\frac{S-1}{\sigma s}, & \text { if } S>0 \\ 0, & \text { if } S=0 \\ \frac{S+1}{\sigma s}, & \text { if } S<0\end{cases}
$$

The null hypothesis that there is no trend is rejected when the computed $Z$ value is greater than $Z_{\alpha / 2}$ in absolute value.

Next, we proceeded to test for stationarity in panel data by applying Levin, Lin, and Chu's (2002) unit root. Levin et al. (2002) proposed to test the null hypothesis of $\mathrm{H}_{0}: \delta=0$ against the alternative hypothesis of $\mathrm{H}_{1}: \delta<0$ using:

$$
\Delta y_{i t}=\delta y_{i t-1}+\sum_{L=1}^{P_{i}} \theta_{i L} \Delta y_{i t-L}+\alpha_{m i} d_{m t}+\varepsilon_{i t}, \quad m=1,2,3
$$

where $d_{m t}$ denotes the deterministic components, $\alpha_{m i}$ denotes the corresponding vector of coefficients for model $m=1,2,3$, and $\varepsilon_{i, t}$ is assumed to be independently distributed across $i$ and $t$ where $i=1, \ldots, N$ and $t=1, \ldots, T$. The normalized bias and the pseudo $t$-ratio that corresponds with the pooled Ordinary Least Squares (OLS) estimation of $\delta$ in Equation (3), once have been properly normalized, converge to a standard limit distribution as $N \rightarrow \infty, T \rightarrow \infty$ in a way that $\sqrt{N} / T \rightarrow 0$.

After the unit root test, the study proceeded to analyze whether climate data and tourism demand data were important contributing factors in the number of dengue cases in Aruba. In order to do this, we tested three types of panel models, i.e.: (1) a pooled OLS regression model; (2) a fixed-effects model (FEM); and (3) a random-effects model (REM). The following equations and methodological analyses were based on Baltagi (2008). The following pooled OLS models were tested:

$$
\begin{gathered}
A U A_{-} \text {DENGUE_IR_SF } F_{i, t}=\alpha_{i, t}+\alpha_{2} A U_{-} C L O A_{-} S F_{i, t}+\alpha_{3} A U A_{-} R A I N_{-} S F_{i, t} \\
+\alpha_{4} A U A_{-} T E M P_{-} S F_{i, t}+\alpha_{5} A U A_{-} M A X_{-} S F_{i, t}+\alpha_{6} A U A_{-} M I N_{-} S F_{i, t} \\
+\alpha_{7} A U A_{-} W I N D_{-} S F_{i, t}+\alpha_{8} A U A_{-} R H_{-} S F_{i, t} \\
+\alpha_{9} T O T_{-} T O R_{-} S F_{i, t}+u_{i, t} \\
T O T_{-} T O U R_{-} S F_{i, t}=\alpha_{i, t}+\alpha_{17} A U A_{-} C L O D_{-} S F_{i, t}+\alpha_{18} A U A_{-} R A I N_{-} S F_{i, t} \\
+\alpha_{19} A U A_{-} T E M P_{-} S F_{i, t}+\alpha_{20} A U A_{-} M A X_{-} S F_{i, t}+\alpha_{21} A U A_{-} M I N_{-} S F_{i, t} \\
+\alpha_{22} A U A_{-} W I N D_{-} S F_{i, t}+\alpha_{23} A U A_{-} R H_{-} S F_{i, t} \\
+\alpha_{24} D E N G U E_{-} I R_{-} S F_{i, t}+u_{i, t} \\
C R U I S E_{-} T O U R_{-} S F_{i, t}=\alpha_{i, t}+\alpha_{25} A U A_{-} C L O U D_{-} S F_{i, t}+\alpha_{26} A U A_{-} R A I N_{-} S F_{i, t} \\
+\alpha_{27} A U A_{-} T E M P_{-} S F_{i, t}+\alpha_{28} A U A_{-} M A X_{-} S F_{i, t}+\alpha_{29} A U A_{-} M I N_{-} S F_{i, t} \\
+\alpha_{30} A U A_{-} W I N D_{-} S F_{i, t}+\alpha_{31} A U A_{-} R H_{-} S F_{i, t} \\
+\alpha_{32} D E N G U E_{-} I R_{-} S F_{i, t}+u_{i, t}
\end{gathered}
$$




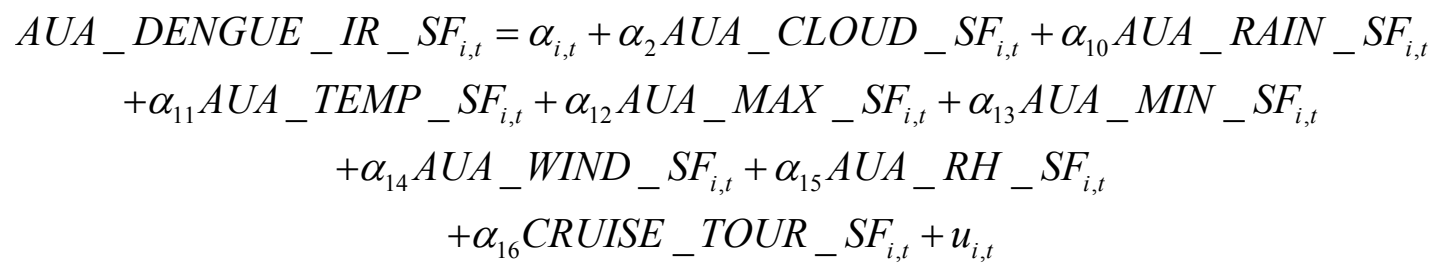

where:

$i=1, \ldots, 12$;

$t=1999, \ldots, 2011$;

$A U A \_D E N G U E \_I R \_S F=$ Dengue irregular and seasonal factors;

$A U A \_C L O U D \_S F=$ Cloud coverage in Aruba seasonal factors;

$A U A \_R A I N \_S F=$ Rainfall in Aruba seasonal factors;

$A U A \_T E M P \_S F=$ Temperature in Aruba seasonal factors;

$A U A \_M A X \_S F=$ Maximum temperature in Aruba seasonal factors;

$A U A \_M I N \_S F=$ Minimum temperature in Aruba seasonal factors;

$A U A \_W I N D \_S F=$ Wind in Aruba seasonal factors;

$A U A \_R H \_S F=$ Relative humidity in Aruba seasonal factors;

TOT_TOUR_SF = Stay-over tourism in Aruba seasonal factors;

CRUISE_TOUR_SF $=$ Cruise tourism in Aruba seasonal factor;

$\alpha$ 's $=$ Coefficients;

$u=$ Residual.

The FEM is indicated as follows:

$$
\begin{aligned}
& \left(A U A_{D E N G U E_{I R_{-} S F_{i}, t}}-\overline{A U A_{D E N G U E_{I R_{-} S F_{i}}}}\right)=\alpha_{33}\left(A U A_{C_{L O U D_{S F_{i}, t}}}-\overline{A U A_{C_{L O U D} F_{F_{i}}}}\right) \\
& +\alpha_{34}\left(A U A_{R^{A I N} N_{S F_{i, t}}}-\overline{A U A_{R A I N_{S F_{i}}}}\right)+\alpha_{35}\left(A U A_{\text {TEMP }_{S F_{i, t}}}-\overline{A U A_{\text {TEMP }_{S F_{i}}}}\right) \\
& +\alpha_{36}\left(A U A_{M A X_{S F_{i, t}}}-\overline{A U A_{M A X_{S F_{i}}}}\right)+\alpha_{37}\left(A U A_{M I N_{S F_{i}, t}}-\overline{A U A_{M I N_{S F_{i}}}}\right) \\
& +\alpha_{38}\left(A U A_{W I N D_{S F_{i, t}}}-\overline{A U A_{W I N D_{S F_{i}}}}\right)+\alpha_{39}\left(A U A_{R H_{S F_{i, t}}}-\overline{A U A_{R H_{S F_{i}}}}\right) \\
& +\alpha_{40}\left(A U A_{\text {TOT_ROUR }_{S F_{i, t}}}-\overline{A U A_{\text {TOT_TOUR }_{S F_{i}}}}\right)+u_{i, t} \\
& \left(A U A_{D E N G U E_{I R_{-} S F_{i, t}}}-\overline{A U A_{D E N G U E_{I R_{-} S F_{i}}}}\right)=\alpha_{41}\left(A U A_{C L O U D_{S F_{i}, t}}-\overline{A U A_{C L O U D_{S F_{i}}}}\right) \\
& +\alpha_{42}\left(A U A_{R A I N_{S F_{i}, t}}-\overline{A U A_{R_{A I N}}}\right)+\alpha_{43}\left(A U A_{\text {TEMP }_{S F_{i}, t}}-\overline{A U A_{T E M P_{S F_{i}}}}\right) \\
& +\alpha_{44}\left(A U A_{M A X_{S F_{i, t}}}-\overline{A U A_{M A X_{S F_{i}}}}\right)+\alpha_{45}\left(A U A_{M_{S_{S F_{i, t}}}}-\overline{A U A_{M I N}}\right) \\
& +\alpha_{46}\left(A U A_{W I N D_{S F_{i}, t}}-\overline{A U A_{W I N D_{S F_{i}}}}\right)+\alpha_{47}\left(A U A_{R H_{S F_{i, t}}}-\overline{A U A_{R H_{S F_{i}}}}\right) \\
& +\alpha_{48}\left(A U A_{\text {CRUISE_TOUR }}-\overline{A F_{F_{i}, t}}-\overline{A_{\text {CRUISE_TOUR }_{S F_{i}}}}\right)+u_{i, t}
\end{aligned}
$$




$$
\begin{aligned}
& \left(A U A_{T T_{-} T O U R_{I R_{-} S F_{i, t}}}-\overline{A U A_{T^{\prime} T_{-}} T_{O U R_{I R_{-} S F_{i}}}}\right)=\alpha_{49}\left(A U A_{\text {CLOUD }_{S F_{i, t}}}-\overline{A U A_{\text {CLOUD }_{S F_{i}}}}\right) \\
& +\alpha_{50}\left(A U A_{R I N_{S F_{i}, t}}-\overline{A U A_{R_{A I N}}}\right)+\alpha_{51}\left(A U A_{T E M P_{S F_{i}, t}}-\overline{A U A_{T E M P_{S F_{i}}}}\right) \\
& +\alpha_{52}\left(A U A_{M A X_{S F_{i}, t}}-\overline{A U A_{M A X_{S F_{i}}}}\right)+\alpha_{53}\left(A U A_{M I N_{S F_{i, t}}}-\overline{A U A_{M I N N_{S F_{i}}}}\right) \\
& +\alpha_{54}\left(A U A_{W I N D_{S F_{i}, t}}-\overline{A U A_{W I N D_{S F_{i}}}}\right)+\alpha_{55}\left(A U A_{R H_{S F_{i}, t}}-\overline{A U A_{R H_{S F_{i}}}}\right) \\
& +\alpha_{56}\left(A U A_{D_{E N G U E_{I R_{-} S F_{i, t}}}}-\overline{A U A_{D E N G U E_{I R_{-} S F_{i}}}}\right)+u_{i, t} \\
& \left(A U A_{\text {CRUISE }_{-} T O U R_{I R_{-} S F_{i, t}}}-\overline{A U A_{\text {CRUISE_TOUR }_{I R_{-} S F_{i}}}}\right)=\alpha_{57}\left(A U A_{\text {CLOUD }_{S F_{i, t}}}-\overline{A U A_{\text {CLOUD }_{S F_{i}}}}\right) \\
& +\alpha_{58}\left(A U A_{R I N_{S F_{i}, t}}-\overline{A U A_{R_{A I N}}}\right)+\alpha_{59}\left(A U A_{T_{i E M P_{S F}}}-\overline{A U A_{T E M P_{S F_{i}}}}\right) \\
& +\alpha_{60}\left(A U A_{M A X_{S F_{i, t}}}-\overline{A U A_{M A X_{S F_{i}}}}\right)+\alpha_{61}\left(A U A_{M I N_{S F_{i, t}}}-\overline{A U A_{M I N}}\right) \\
& +\alpha_{62}\left(A U A_{W I N D_{S F_{i}, t}}-\overline{A U A_{W I N D_{S F_{i}}}}\right)+\alpha_{63}\left(A U A_{R H_{S F_{i}, t}}-\overline{A U A_{R H_{S F_{i}}}}\right) \\
& +\alpha_{64}\left(A U A_{D E N G U E_{I R_{-} S F_{i, t}}}-\overline{A U A_{D E N G U E_{I R_{-} S F_{i}}}}\right)+u_{i, t}
\end{aligned}
$$

To determine whether the FEM is superior to the pooled OLS model, we calculated a restricted $F$-test, which compares the coefficients of determination of both pooled OLS and FEM (Gujarati, 2011).

The REM model is expressed as follows:

$$
\begin{gathered}
A U A_{-} \text {DENGUE_IR_SF } F_{i, t}=\alpha_{i, t}+\alpha_{65} A U A_{-} C L O U D_{-} S F_{i, t}+\alpha_{66} A U A_{-} R A I N_{-} S F_{i, t} \\
+\alpha_{67} A U A_{-} T E M P_{-} S F_{i, t}+\alpha_{68} A U A_{-} M A X_{-} S F_{i, t}+\alpha_{69} A U A_{-} M I N_{-} S F_{i, t} \\
+\alpha_{70} A U A_{-}{ } W I N D_{-} S F_{i, t}+\alpha_{71} A U A_{-} R H_{-} S F_{i, t} \\
+\alpha_{72} T O T_{-} T O U R_{-} S F_{i, t}+w_{i, t}
\end{gathered}
$$

where $w_{i, t}=\varepsilon_{i}+u_{i, t}$.

$$
\begin{gathered}
A U A_{-} \text {DENGUE_IR_S } S F_{i, t}=\alpha_{i, t}+\alpha_{73} A U A_{-} C L O U_{-} S F_{i, t}+\alpha_{74} A U A_{-} R A I N_{-} S F_{i, t} \\
+\alpha_{75} A U A_{-} T E M P_{-} S F_{i, t}+\alpha_{76} A U A_{-} M A X_{-} S F_{i, t}+\alpha_{77} A U A_{-} M I N_{-} S F_{i, t} \\
+\alpha_{78} A U A_{-} W_{-} D_{-} S F_{i, t}+\alpha_{79} A U A_{-} R H_{-} S F_{i, t} \\
+\alpha_{80} C R U I S E_{-} T O U R_{-} S F_{i, t}+w_{i, t}
\end{gathered}
$$

where $w_{i, t}=\varepsilon_{i}+u_{i, t}$.

$$
\begin{gathered}
\text { TOT_TOUR_SF } F_{i, t}=\alpha_{i, t}+\alpha_{81} A U A_{-} C L O U D_{-} S F_{i, t}+\alpha_{82} A U A_{-} R A I N_{-} S F_{i, t} \\
+\alpha_{83} A U A_{-} T E M P_{-} S F_{i, t}+\alpha_{84} A U A_{-} M A X_{-} S F_{i, t}+\alpha_{85} A U A_{-} M I N_{-} S F_{i, t} \\
+\alpha_{86} A U A_{-} W_{-} D_{-} S F_{i, t}+\alpha_{87} A U A_{-} R H_{-} S F_{i, t} \\
+\alpha_{88} D E N G U E_{-} I R_{-} S F_{i, t}+w_{i, t}
\end{gathered}
$$

where $w_{i, t}=\varepsilon_{i}+u_{i, t}$. 


$$
\begin{gathered}
\text { CRUISE_SF } F_{i, t}=\alpha_{i, t}+\alpha_{89} A U A_{-} C L O U D_{-} S F_{i, t}+\alpha_{90} A U A_{-} R A I N_{-} S F_{i, t} \\
+\alpha_{91} A U A_{-} T E M P_{-} S F_{i, t}+\alpha_{92} A U A_{-} M A X_{-} S F_{i, t}+\alpha_{93} A U A_{-} M I N_{-} S F_{i, t} \\
+\alpha_{94} A U A_{-}{ } W I N D_{-} S F_{i, t}+\alpha_{95} A U A_{-} R H_{-} S F_{i, t} \\
+\alpha_{96} D E N G U E_{-} I R_{-} S F_{i, t}+w_{i, t}
\end{gathered}
$$

where $w_{i, t}=\varepsilon_{i}+u_{i, t}$.

Essentially, the error term $w_{i, t}$ is composed of an individual-specific error $\left(\varepsilon_{i}\right.$, with a mean of zero and variance of $\sigma_{\varepsilon}^{2}$ ) and a combined time series and cross-section error component. Additionally, the REM assumes that the intercept of any cross-section unit is not fixed, but a random variable with a mean value of $\alpha_{1}$ can thus be expressed as:

$$
\alpha_{1, i}=\alpha_{1}+\varepsilon_{i}
$$

The Hausman test was conducted to investigate the adequacy of the REM against the FEM, where the null hypothesis is that both the FEM and the REM do not differ significantly. The test involves a comparison of a calculated $\chi^{2}$ against a critical $\chi^{2}$. If the calculated $\chi^{2}$ is larger than the critical $\chi^{2}$, we can then conclude that the REM is not the appropriate model and that the FEM is preferred to be over REM (Baltagi, 2008). The Breusch-Pagan Lagrange multiplier (LM) test was also conducted to investigate the adequacy of the REM against the pooled OLS. The Breusch-Pagan LM test's null hypothesis is that the variance across entities is zero (Torres-Reyna, 2014).

Based on the results of the models, we calculated the monthly differences between the seasonal factors of dengue cases and the statistically significant seasonal factors of tourism. The results of these calculations will provide indications of the strength of association during several periods of the year. For this purpose, we used the Mahalanobis distance measure formula. The Mahalanobis distance is the distance between two points in a $k$-dimensional space, scaled by the statistical variation in each dimension of the space. For instance, if $x$ and $y$ are two observations on a set of $k$ variables with covariance matrix $C$, then the Mahalanobis distance between the observations is given by $\sqrt{(x-y)^{\prime} C^{-1}(x-y)}$ where $(x-y)$ is a $k$-vector (Cottrell \& Lucchetti, 2012). The smaller the Mahalanobis distance result, the stronger the influence of the variables with each other. Mahalanobis distance calculation was used in other epidemiology studies, such as the European Centre for Disease Prevention and Control, to assess areas vulnerable to dengue in Europe. In their study, this institute used the Mahalanobis distance to gauge the degree of climatic difference that exists between Europe and the known places of dengue transmission (European Centre for Disease Prevention and Control, 2012).

\section{Results and Discussion}

All estimates were obtained from using the following combinations of software, Eviews, Gretl, Stata and R. Firstly, all variables were subjected to power transformations. The best transformation parameter was chosen using Hinkley's $d_{\lambda}$ statistic (Wilks, 1995) (see Table 2). After the appropriate power transformation, regression results show that most of the variables have the additive form, with the exception of the variables $A U A_{-} R H$ and $A U A \_M I N$ which were found to be multiplicative (see Table 3), based on a $\alpha$-value of 0.05 . According to Ellison and Gotelli (2004), using a low critical value as 0.05 , one can be confident that the patterns in the data can be quite strong; humans are psychologically predisposed to recognizing and seeing patterns in data even if they do not exist and a low critical value would safeguard against this. 
Table 2

Best $\lambda$ Used for Power Transformation

\begin{tabular}{lc}
\hline Variable & $\lambda$ \\
\hline AUA_DENGUE & 0 \\
AUA_CLOUD & 1 \\
AUA_RH & -0.5 \\
AUA_RAIN & 0 \\
AUA_TEMP & 1 \\
AUA_WIND & 1 \\
AUA_MAX & 1 \\
AUA_MIN & 1 \\
CRUISE_TOUR & 1 \\
TOT_TOUR & 0 \\
\hline
\end{tabular}

Table 3

Model Type on Monthly Data

\begin{tabular}{llll}
\hline Variable & Regression result of $\beta$ & Model type & $p$-value $5 \%$ \\
\hline AUA_DENGUE & 0.036853 & Additive & 0.39 \\
AUA_CLOUD & -0.013634 & Additive & 0.86 \\
AUA_RAIN & -0.04328 & Additive & 0.74 \\
AUA_TEMP & -0.240273 & Additive & 0.11 \\
AUA_WIND & -0.11038 & Additive & 0.14 \\
AUA_RH & 0.198499 & Multiplicative & 0.00 \\
AUA_MIN & -0.2757 & Multiplicative & 0.03 \\
AUA_MAX & -0.003725 & Additive & 0.94 \\
CRUISE_TOUR & 0.260215 & Additive & 0.06 \\
TOT_TOUR & 0.007241 & Additive & 0.88 \\
\hline
\end{tabular}

Table 4

Explanatory Power of Time-Series Elements

\begin{tabular}{llll}
\hline Dependent variable & Adj. $R^{2}$ IR & Adj. $R^{2}$ TC & Adj. $R^{2}$ SF \\
\hline d_AUA_CLOUD & 0.50 & 0.02 & 0.48 \\
d_AUA_RH & 0.70 & 0.08 & 0.22 \\
d_AUA_RAIN & 0.71 & 0.09 & 0.20 \\
d_AUA_TEMP & 0.20 & 0.11 & 0.69 \\
d_AUA_WIND & 0.45 & 0.03 & 0.52 \\
d_AUA_MAX & 0.74 & 0.03 & 0.23 \\
d_AUA_MIN & 0.32 & 0.06 & 0.62 \\
d_AUA_DENGUE & 0.71 & 0.05 & 0.24 \\
d_CRUISE_TOUR & 0.14 & 0.00 & 0.86 \\
d_TOT_TOUR & 0.15 & 0.05 & 0.80
\end{tabular}

Notes. $d_{-}=$First difference of variable; Adj. $R^{2}=$ Adjusted coefficient of determination. The higher the Adj. $R^{2}$ is, the more explanatory power an element of the variable has; $\mathrm{IR}=$ Irregular values, $\mathrm{TC}=$ Trend-cycle values, $\mathrm{SF}=$ Seasonal values.

The regression results from the analysis of short-term explanatory power indicate that indeed, both seasonal and irregular factors explained most of the short-range variability of the series, with the seasonal factors explaining more than $50 \%$ of the variability in stay-over tourism, cruise tourism, average temperature, average minimum temperature, and wind speed in Aruba (see Table 4 above). This suggests that the causation 
of the short-term volatility of the indicated variables is largely due to repeating factors over time. With respect to dengue incidences, $24 \%$ of the short-term change was due to seasonal factors, while $71 \%$ was due to irregular factors ( $\left.A U A \_D E N G U E_{-} I R_{-} S F\right)$. Given the last outcome, we proceeded to define dengue incidences as a combined factor of irregular and seasonal factors. The other variables remained as seasonal factors, in order to see if the seasonality of the variables can still be used to explain dengue occurrence in Aruba. After the regression results from the analysis of short-term explanatory power, the remaining series were standardized.

Table 5

Mann-Kendall Results

\begin{tabular}{|c|c|c|}
\hline Seasonal value & Characteristic & Probability \\
\hline$\overline{A U A \_D E N G U E}$ & Trend & 0.00 \\
\hline AUA_CLOUD & Trend & 0.00 \\
\hline$A U A \_R H$ & Trend & 0.00 \\
\hline$A U A \_R A I N$ & Trend & 0.00 \\
\hline$A U A \_T E M P$ & Trend & 0.00 \\
\hline$A U A \_W I N D$ & Trend & 0.00 \\
\hline$A U A \_M A X$ & Trend & 0.00 \\
\hline$A U A \_M I N$ & Trend & 0.00 \\
\hline CRUISE_TOUR & Trend & 0.00 \\
\hline STAYOVER & No trend & 0.42 \\
\hline$A U A D E N G U E I R S F$ & Trend & 0.00 \\
\hline
\end{tabular}

Table 6

Panel Unit Root Results

\begin{tabular}{|c|c|c|c|c|}
\hline Variable & $\mathrm{I}(0)$ degree of integration & I(1) degree of integration & $\mathrm{I}(2)$ degree of integration & Assumption \\
\hline$A U A \_C L O U D \_S F$ & $-16^{* * *}$ & & & Intercept and trend \\
\hline$A U A \_R A I N \_S F$ & $-10.7277^{* * *}$ & & & Intercept and trend \\
\hline$A U A \_R H \_S F$ & $-2.21377^{* * *}$ & & & Intercept and trend \\
\hline$A U A \_T E M P \_S F$ & $-19.9411^{* * *}$ & & & Intercept and trend \\
\hline$A U A \_W I N D \_S F$ & & $-1.6154^{* *}$ & & Intercept and trend \\
\hline$A U A \_M A X \_S F$ & $-8.00545^{* * *}$ & & & Intercept and trend \\
\hline$A U A \_M I N \_S F$ & $-8.24008^{* * *}$ & & & Intercept and trend \\
\hline$A U A \_D E N G U E \_S F$ & $-18^{* * *}$ & & & Intercept and trend \\
\hline$A U A \_D E N G U E \_I R \_S F$ & $-8.49^{* * *}$ & & & Intercept and trend \\
\hline CRUISE_TOUR_SF & $-21.3229^{* * *}$ & & & Intercept and trend \\
\hline TOT_TOUR_SF & $-6.37573^{* * *}$ & & & Intercept \\
\hline
\end{tabular}

Notes. ${ }^{* * *}$, , and " reflect significance at the levels of $1 \%, 5 \%$, and $10 \%$, respectively. $\mathrm{SF}=$ Seasonal factors; $\mathrm{SA}=$ Seasonal adjusted factors.

After standardization, all variables were transformed to panel data, and a Mann-Kendall trend test was conducted, in order to delineate whether both intercept and trend should be applied in the unit root equation (see Table 5 above). The results indicate in most cases that both trend and intercept should be applied. Afterwards, the test for stationarity, using Levin et al.'s (2002) unit root test, was conducted. The maximum lag selection was based on the Schwarz Information Criterion. The results are included in Table 6 above and show that most variables are integrated of zero order, meaning that they are already stationary. Only the seasonal variable representing wind showed signs of being I(1). Therefore, this variable was dropped, and we proceeded 
with the stationary variables only. Since the remaining variables were integrated at level order, no cointegration is possible (Asteriou \& Hall, 2007). Table 7 provides the results of the tested equations. The variables $A U A \_M I N \_S F$ and $A U A \_T E M P \_S F$ were dropped from the regressions due to collinearity, given that their variance inflation factors were above 10 (Kennedy, 2013).

Table 7

Panel Regression Results

\begin{tabular}{lllll}
\hline Variable & Pooled OLS & REM & FEM & REM \\
& $A U A \_D E N G U E \_I R \_S F$ & $A U A \_D E N G U E \_I R \_S F$ & $C R U I S E \_T O U R \_S F$ & $T O T \_T O U R \_S F$ \\
\hline$A U A \_C L O U D \_S F$ & $-0.24^{* *}$ & $-0.60^{* * *}$ & 0.06 & $-0.29^{* * *}$ \\
AUA_RH_SF & 0.02 & -0.02 & 0.00 & 0.07 \\
AUA_RAIN_SF & -0.07 & 0.09 & $-0.21^{* * *}$ & 0.08 \\
AUA_MAX_SF & 0.02 & 0.04 & $0.14^{* * *}$ & $0.11^{* * *}$ \\
CRUISE_TOUR_SF & $0.69^{* * *}$ & & & \\
TOT_TOUR_SF & & -0.02 & & \\
AUA_DENGUE_IR_SF & & 0.015 & 0.01 \\
\hline
\end{tabular}

Notes. ${ }^{* * *}$, and ${ }^{* * *}$ indicate significance at the levels of $90 \%, 95 \%$, and $99 \%$, respectively. SF $=$ Seasonal factors; IR $=$ Irregular factors.

The first equation calculated was $A U A \_D E N G U E_{-} I R \_S F$ as an independent variable, and $A U A \_R A I N \_S F, A U A \_M A X \_S F, A U A \_R H \_S F, A U A \_C L O U D \_S F$, and TOT_TOUR_SF as dependent variables. The Breusch-Pagan test showed that the REM is superior to the pooled OLS (AUA_DENGUE_IR_SF: 16.99, $p=0.000$ ) and the Hausman test showed that the REM is superior to the FEM for the purpose of estimating the impact of seasonal factors of dengue incidences on the tourism demand variables and climate variables (AUA_DENGUE_IR_SF: 7.47, $p=0.187)$. We, therefore, used the REM model for the estimates. No relationship was noted with respect to the seasonal movement of stay-over tourism (TOT_TOUR_SF) and dengue. Since the stay-over tourist is defined as a tourist who arrives by airplanes and stays at least 24 hours in Aruba, this indicates that the virus is not imported via airplanes to Aruba and the stay-over tourist does not act as a host to disperse the virus in Aruba. Possible stay-over visitors infected with the virus would probably cancel the airline trip or postpone it till they recover. In addition, most stay-over tourists (63.5\%) arrive from USA and most of them from the Northeast sector (Ridderstaat et al., 2014). The prevalence of dengue in the Northeast sector of USA is also low (Centers for Disease Control and Prevention [CDC], 2014). Therefore, we would expect a no-relationship between dengue incidences and stay-over tourists. The only significant value was for cloud amount, hinting an increase in dengue when there is less cloud. Cloud amount in Aruba fluctuates a lot. On one hand, one can expect an increase in cloud coverage during the dry season due to upper-level clouds. On the other hand, decreases and increases can be observed during the wet season. Since no relationship was found with rainfall, we could assume that dengue incidence fluctuations observed with cloud coverage fluctuations are not rain-related. Moreno (2010) observed that beach tourists are drawn or withdrawn by certain climate factors, for example, precipitation, wind, hours of sunlight, and cloud coverage, which all fall within the aesthetic facet of climate and have an influence on enjoyment and attractiveness of a site (De Freitas, 2001). Therefore, weather variables, such as cloud amount, can trigger certain human responses. Gubler and Kuno (1997) indicated that the probability of contact among human, virus, and mosquito is easier in any aedes aegypti-infected location where people congregate, resulting in transmission either from an infective vector to a host or from a viremic host to an uninfected vector. 
Therefore, less cloud coverage will probably cause more people to congregate outdoor and aid in the transmission of the virus. Of interest was that we found no statistical relationship with rainfall in Aruba. This contradicts other studies conducted in the Caribbean (Chadee, Shivnauth, Rawlins, \& Chen, 2007), which did see a seasonal relationship between rainfall and dengue. On the other hand, studies done by Gubler and Kuno (1997) and Lu, Lin, Tian, Yang, Sun, and Liu (2009) showed that at times, no correlation could be established between rainfall and dengue.

The second equation calculated was $A U A_{-} D E N G U E_{-} I R_{-} S F$ as an independent variable, and $A U A \_R A I N \_S F, A U A \_M A X \_S F, A U A \_R H \_S F, A U A \_C L O U D \_S F$, and CRUISE_TOUR_SF as dependent variables. The Breusch-Pagan test (AUA_DENGUE_IR_SF: 0.244, $p=0.621)$, the Hausman test ( $\left.A U A \_D E N G U E \_I R \_S F: 5.57, p=0.350\right)$, and the $F$-statistic test $\left(A U A \_D E N G U E_{-} I R \_S F: 1.787, p=0.062\right)$ showed that pooled OLS is the most superior model for this relationship. Since we are using pooled OLS and in pooled OLS, standard errors can be serially correlated, we proceeded, according to Cameron and Trivedi (2005) to control for this by clustering the standard errors on the panel unit index (month) variable. The model indicated that cruise tourism (CRUISE_TOUR_SF) would have a positive effect on dengue incidences.

In the last decades, the passenger shipping industry, including cruise ships, has expanded considerably. The World Health Organization (WHO) indicates that in 2008, 13 million passengers travelled by cruise ships to all continents, including areas that are not easily accessible by other means of travel. On average, a cruise lasts about seven days, but some can last several months. Cruise ships can carry now, on average, 3,000 passengers and 1,000 crew (WHO, 2010). In Aruba, the number of cruise calls in 1981 was 79 and increased to 332 in 2011, a growth rate of 320\%. The number of cruise visitors in 1981 was 54,971 and 599,893 in 2011, which indicates a whopping growth rate of almost $991 \%$ (Aruba Central Bureau of Statistics, 2014). A cruise survey done by Aruba Central Bureau of Statistics in 2002 indicated that almost 59\% cruise-surveyed tourists came from the US. Another survey conducted in 1997 indicated that almost $68 \%$ came from the US, which would hint that the proportion of tourists from other countries is increasing on the cruise ships visiting Aruba (Aruba Central Bureau of Statistics, 2014).

The increase in dengue-related cases to increase in cruise tourism could have a dual explanation. First, this could indicate that tourists coming through the harbor could be carrying the virus; therefore, they are likely to introduce the virus to the available vectors (mosquitoes), which later infect the local population. On a cruise ship, one can expect different nationalities, where a cruise vacation may involve many stops. Passengers may also be dropped off or picked up at multiple ports. All these patterns increase the potential risks of infectious disease exposures (WHO, 2010). Data corroborate that cruise ships have served as a mode of disease outbreaks, where passengers then disperse the infection elsewhere. The closed and crowded environment on a ship allows an easy transmission of pathogens and the short durations of the cruise can allow an infected tourist to reach another location before the onset of symptoms (Chen \& Wilson, 2008). For example, in 1990, a passenger on board a ship became the index case of an outbreak and influenced 205 local residents in Italy (Chen \& Wilson, 2008). The passenger was infected with chikungunya and passed the virus to mosquitoes, which passed it to the local population. Chikungunya is another viral disease that can be transmitted the same way as dengue and has roughly the same incubation period (Chakraborty, 2008). The WHO estimates that in the last 30 years, more than 100 disease outbreaks were related with ships. The WHO states that the number of reported outbreaks might be an underestimate, since many go undetected or are not reported (WHO, 2010). As dengue has a short incubation period, a passenger can acquire the virus at another 
port of call and becomes viremic when reaching Aruba. Once in Aruba, the passenger is able to pass it along the vectors. A survey conducted by Aruba Central Bureau of Statistics in 2002 indicated that almost $80 \%$ of the money spent in Aruba by a cruise tourist would be done in shopping. Since almost all stores that cruise tourists visit are close to the cruise terminal in downtown Oranjestad, this would automatically create a convergence flux of people downtown, while the cruise ship is in harbor, thus increasing the chances of virus transmission (Aruba Central Bureau of Statistics, 2014).

Second, except for cruise ships introducing infected hosts, there also exists a probability that the infected vector was transported on a ship (Gubler \& Kuno, 1997; Halstead, 2008). Therefore, the "illegal" vector will introduce the virus to the local population and afterwards, the virus is further distributed via the regular manner. According to Halstead (2008), adult mosquitoes can be transported through various sources, but both aedes aegypti and aedes albopictus are now very widely distributed around the world, thus making the transport of viremic humans a more important mechanism now responsible for the introduction of dengue viruses across national borders instead of an "illegal" vector. Hence, one would expect that the chance of an infected tourist coming on shore and passing the virus to the available vectors would be bigger than the chance of the virus being carried by an infected vector coming on shore. As was the case for the earlier equation, we noticed here again that the value of cloud amount showed a significant negative relationship with respect to dengue incidences. Same reasoning can be applied for the explanation of this variable.

The third equation calculated had TOT_TOUR_SF as an independent variable, and $A U A \_R A I N \_S F$, $A U A \_M A X \_S F, A U A \_R H \_S F, A U A \_C L O U D \_S F$, and $A U A \_D E N G U E_{-} I R \_S F$ as dependent variables. The $F$-statistics (AUA_DENGUE_IR_SF: 232.159, $p=0.000)$, the Breusch-Pagan test (AUA_DENGUE_IR_SF: $719.752, p=0.000)$, and the Hausman test $\left(A U A \_D E N G U E \_I R \_S F: 3.30, p=0.654\right)$ showed that the REM was superior to the FEM and the pooled OLS. Dengue incidences had no relation to stay-over tourism incidences. This further corroborates the earlier conclusion that stay-over tourism fluctuations had no influence on dengue as the dependent variable. This also shows that it is possible that the so-called lock-in effect has an influence on Aruba. The lock-in effect means that even under changing circumstances, the amount of tourism visits stays the same. For example, Moreno (2010) indicated that as much of 54\% of Europeans preferred to spend their vacations in conventional, well-known tourist destinations and would not change their plans due to changing circumstances. In the case of Aruba, a changing circumstance could increase dengue cases, but even so, the tourist would still choose Aruba as a destination, due to its popularity.

The fourth equation had CRUISE_TOUR_SF as an independent variable, and $A U A \_R A I N_{-} S F$, $A U A_{-} M A X \_S F, A U A_{-} R H \_S F, A U A_{-} C L O U D \_S F$, and $A U A \_D E N G U E_{-} I R \_S F$ as dependent variables. The $F$-statistics showed that the FEM was superior to the pooled OLS ( $A U A \_D E N G U E_{-} I R \_S F: 239.405, p=0.025$ ). The Breusch-Pagan test showed that the REM is superior to the pooled OLS (AUA_DENGUE_IR_SF: 429.919, $p=0.000$ ). The Hausman test showed that the FEM is superior to the REM for the purpose of estimating the impact of seasonal factors of dengue incidences on the tourism demand variables and climate variables ( $A U A$ DENGUE_IR_SF: 35.349, $p=0.000$ ). We, therefore, conclude that the FEM model is superior to the other models. The model showed that dengue incidences cannot cause cruise tourism to increase or decrease, while earlier we showed that cruise tourism itself could have an influence on dengue cases. This again can be explained by the earlier-mentioned lock-in effect. 
The Mahalanobis distances were subsequently calculated for seasonal factors of cruise tourism (CRUISE_TOUR_SF), cloud amount (AUA_CLOUD_SF), and fluctuations of dengue incidences. Table 8 indicates the months where the Mahalanobis distance outcomes were smaller than the average; this can be used as a proxy when the sensitivity of the seasonal factors of dengue incidences to those of cruise tourism and cloud coverage was the highest. Here, one can deduce that sensitivity to seasonal factors of cruise tourism was the most pertinent in the months of February, April-July, and October-November and in the months of March, June-July, September, November, and December for cloud amount.

Table 8

Months Where Mahalanobis Distance is Below Average

\begin{tabular}{llc}
\hline Month of the year & \multicolumn{2}{c}{ Dengue } \\
\cline { 2 - 3 } & Cruise tourism & Cloud amount \\
January & $\bullet$ & $\bullet$ \\
March & & \\
April & $\bullet$ & $\bullet$ \\
May & $\bullet$ & $\bullet$ \\
June & $\bullet$ & $\bullet$ \\
July & $\bullet$ & \\
August & & $\bullet$ \\
Octoptember & & $\bullet$ \\
November & $\bullet$ & \\
December & &
\end{tabular}

Note. $\bullet$ indicates that the Mahalanobis distance is below its average.

Since cruise tourists are not measured by countries of origin in Aruba every year and the trip is usually already under way for a while, one can assume that most tourists would not cancel their cruises to avoid Aruba in case of a dengue outbreak. Moreover, if they acquired dengue symptoms, they would still stay on the cruise and continue their travel, as was the case in Italy with chikungunya (Chen \& Wilson, 2008). Since most cruises do not originate from Aruba and cruise tourists are not, on a regular basis, archived statistically on departure of origin upon arrival in Aruba, we could not use the Mahalanobis distance sensitivity idea to track the climatological condition at the originating tourist country that could influence dengue transmission. Therefore, we could not calculate the chances that the tourist would get infected at his/her departing country before arriving in Aruba. Additionally, most tourists would have passed through different ports of call before arriving in Aruba, making any calculations on where a tourist could have gotten infected almost impossible.

\section{Conclusion}

Dengue is the most critical viral vector-borne disease and a growing problem globally (Gratz \& Knudsen, 1996). Studies recommend that if one eliminates vector-borne diseases such as malaria, it may manifest positively in foreign direct investments, including tourism growth (Sabot et al., 2010). The purpose of this study was to investigate the influence of seasonal patterns of dengue on stay-over tourism, cruise tourism, and climate patterns. This study found that as the number of cruise tourists increased, dengue would also increase in Aruba. A bilateral connection was also studied, but no relation was found between an increase of dengue in Aruba and a decrease of tourists (stay-over and cruise) in Aruba. 
Economists calculate the burden of vector-borne diseases as the sum of the cost of illness and the cost of intervention programs (Mavalankar et al., 2009), where the cost of the illness includes both direct (medical costs) and indirect costs (value of the lost time entailing lost wages, etc.) (Suaya et al., 2007). Yoshikawa and Kusriastuti (2013) showed that the average cost related with one case of dengue in Malaysia would be US\$445 of the government health care budget being spent on the disease. In Thailand, it was estimated in 2005 at US\$573 for non-fatal hospitalization of dengue infection. In Aruba, it is estimated that a cruise tourist would spend around US\$112 a day (Aruba Central Bureau of Statistics, 2014). This shows as a paradox that even though the cruise tourist would spend money in Aruba, it could leave a bigger cost behind.

Due to the relationship between cruise tourism and dengue incidences in Aruba, it is recommended to increase vector surveillance and control near the harbor area of Oranjestad, Aruba where cruise ships dock. According to Gubler and Kuno (1997), passive dispersal is common by all types of transport, including trains, ships, and planes. Therefore, the International Sanitary Regulations require that an area within $400 \mathrm{~m}$ of international ports and airports be kept free of aedes aegypti. Except for the vector surveillance, dengue surveillance among cruise travelers is advisable since residents are exposed to the dengue virus through international travelers. Dengue surveillance in travelers would also serve to exclude the possibility of importation of other serious diseases that can spread to other persons by secondary transmission. Now with the emergence of chikungunya, another arthropod virus transmitted to humans by aedes species, in the Caribbean, it is of greater importance that governments, such as in Aruba, increase their vector surveillance and control strategies (Pan American Health Organization [PAHO], 2014). Since there is no vaccine for dengue, transmission can only be reduced by measures against the mosquito. Many countries have dengue control programs; with limited exceptions, these were far less effective than their yellow fever forerunners (Gubler \& Kuno, 1997). Several factors have been attributed to this limited success, namely, explosive growth of urban areas, limited government sources, poor management, resistance to insecticide, overemphasis on government intervention, and insufficient education of the public (Gubler \& Kuno, 1997). Since 1985, the PAHO relinquished the goal of hemispheric eradication and endorsed the concept of the elimination of dengue through control of aedes aegypti. PAHO also introduced the concept of integrated vector control, where countries should combine all available control methods in the most effective, economical, and safe manner to maintain vector populations at reasonable levels (PAHO, 1994).

Future research should focus on extending this investigation to further investigate the tourism markets for Aruba itself, for example, North American, European, and Asian countries, to get a more complete picture of the influence of dengue and tourism in Aruba. Moreover, this study could be expanded to include other destinations in the Caribbean. It is also recommended that in order to improve the current understanding of the complex dengue systems, the development of an integrated assessment model that includes evolutionary, spatial, and local dynamics of ecological, environmental, social, demographic, and behavioral factors be applied in Aruba.

\section{References}

Aruba Central Bureau of Statistics. (2014). Cruise survey 1997 and 2002. Retrieved from http://www.cbs.aw

Asteriou, D., \& Hall, S. G. (2007). Applied econometrics: A modern approach using eviews and microfit. New York, N.Y.: Palgrave Macmillan.

Baltagi, B. (2008). Econometric analysis of panel data. New York, N.Y.: John Wiley \& Sons.

Cameron, A. C., \& Trivedi, P. K. (2005). Microeconometrics: Methods and applications. Cambridge: Cambridge University Press. 
Centers for Disease Control and Prevention [CDC]. (2014). CDC-dengue. Centers for Disease Control and Prevention. Retrieved from http://www.cdc.gov/dengue/

Chadee, D. D., Shivnauth, B., Rawlins, C. S., \& Chen, A. A. (2007). Climate, mosquito indices, and the epidemiology of dengue fever in Trinidad (2002-2004). Annals of Tropical Medicine and Parasitology, 101(1), 69-77.

Chakraborty, T. (2008). Dengue fever and other hemorrhagic viruses. New York, N.Y.: Chelsea House.

Chen, L. H., \& Wilson, M. E. (2008). The role of the traveler in emerging infections and magnitude of travel. Medical Clinics of North America, 92(6), 1409-1432.

Cobelens, F. G., Groen, J., Osterhaus, A. D., Leentvaar-Kuipers, A., Wertheim-van Dillen, P. M., \& Kager, P. A. (2002). Incidence and risk factors of probable dengue virus infection among Dutch travellers to Asia. Tropical Medicine and International Health, 7(4), 331-338.

Cole, S., \& Razak, V. (2009). How far, and how fast? Population, culture, and carrying capacity in Aruba. Futures, 41(6), 414-425.

Cottrell, A., \& Lucchetti, R. (2012). Gretl user's guide. Distributed with the Gretl Library.

Croes, R. R. (2006). A paradigm shift to a new strategy for small island economies: Embracing demand side economics for value enhancement and long term economic stability. Tourism Management, 27(3), 453-465.

De Freitas, C. R. (2001). Theory, concepts, and methods in tourism climate research. Proceedings of the First International Workshop on Climate, Tourism, and Recreation (pp. 3-20), International Society of Biometeorology.

Den Butter, F. A. G., \& Fase, M. M. G. (1991). Seasonal adjustment as a practical problem. North-Holland: Elsevier Science Publishers.

Departamento Meteorologico Aruba. (2014). Retrieved from http://www.meteo.aw

Eisenhardt, K. M., \& Graebner, M. E. (2007). Theory building from cases: Opportunities and challenges. Academy of Management Journal, 50(1), 25-32.

Ellison, G. N., \& Gotelli, N. J. (2004). A primer of ecological statistics. Massachusetts: Sinauer.

European Centre for Disease Prevention and Control. (2012). The climatic suitability for dengue transmission in continental Europe. Retrieved from http://ecdc.europa.eu/en/publications/publications/ter-climatic-suitablility-dengue.pdf

Gharbi, M., Quenel, P., Gustave, J., Cassadou, S., Ruche, G. L., Girdary, L., \& Marrama, L. (2011). Time series analysis of dengue incidence in Guadeloupe, French West Indies: Forecasting models using climate variables as predictors. $B M C$ Infectious Diseases, 11(1), 166.

Goeldner, C. R., \& Ritchie, J. B. (2009). Tourism: Principles, practices, philosophies. Hoboken, N.J.: John Wiley \& Sons.

Goh, C. (2012). Exploring impact of climate on tourism demand. Annals of Tourism Research, 39(4), 1859-1883.

Gratz, N. G., \& Knudsen, A. B. (1996). The rise and spread of dengue, dengue haemorrhagic fever, and its vectors. A historical review (up to 1995). Geneva: World Health Organization.

Gubler, D. J., \& Kuno, G. (1997). Dengue and dengue hemorrhagic fever. Wallingford, U.K.: CAB International.

Gujarati, D. N. (2011). Econometrics by example. Hampshire, U.K.: Palgrave Macmillan.

Halstead, S. B. (2008). Dengue (Vol. 5). London: Imperial College Press.

Hart, R. E., \& Grumm, R. H. (2001). Using normalized climatological anomalies to rank synoptic-scale events objectively. Monthly Weather Review, 129(9), 2426-2442.

Kennedy, P. (2013). A guide to econometrics. Cambridge, Massachusetts: MIT Press.

Kovats, R., Campbell-Lendrum, D., Reid, C., \& Martens, P. (2000). Climate and vectorborne disease: An assessment of the role of climate in changing disease patterns. Maastricht: ICIS/UNEP/LSHTM.

Levin, A., Lin, C. F., \& Chu, C. S. J. (2002). Unit root tests in panel data: Asymptotic and finite-sample properties. Journal of Econometrics, 108(1), 1-24.

Lu, L., Lin, H., Tian, L., Yang, W., Sun, J., \& Liu, Q. (2009). Time series analysis of dengue fever and weather in Guangzhou, China. BMC Public Health, 9(1), 395.

Lundberg, D. E., Krishnamoorthy, M., \& Stavenga, M. H. (1995). Tourism economics. New York, N.Y.: John Wiley \& Sons.

Maartens, F., Sharp, B., Curtis, B., Mthembu, J., \& Hatting, I. (2007). The impact of malaria control on perceptions of tourists and tourism operators concerning malaria prevalence in KwaZulu-Natal, 1999/2000 versus 2002/2003. Journal of Travel Medicine, 14(2), 96-104.

Matzarakis, A. (2006). Weather- and climate-related information for tourism. Tourism and Hospitality Planning and Development, 3(2), 99-115. 
Mavalankar, D. V., Puwar, T. I., Murtola, T. M., \& Vasan, S. S. (2009). Quantifying the impact of chikungunya and dengue on tourism revenues. IIMA Working Papers, No WP2009-02-03, Indian Institute of Management Ahmedabad, Research and Publication Department.

Mavromatis, T., \& Stathis, D. (2011). Response of the water balance in Greece to temperature and precipitation trends. Theoretical and Applied Climatology, 104(1-2), 13-24.

Meltzer, M. I., Rigau-Perez, J. G., Clark, G. G., Reiter, P., \& Gubler, D. J. (1998). Using disability-adjusted life years to assess the economic impact of dengue in Puerto Rico: 1984-1994. The American Journal of Tropical Medicine and Hygiene, 59(2), 265-271.

Moreno, A. (2010). Climate change and tourism: Impacts and vulnerability in coastal Europe (Doctoral thesis, Universitaire Pers Maastricht).

Onoz, B., \& Bayazit, M. (2003). The power of statistical tests for trend detection. Turkish Journal of Engineering and Environmental Sciences, 27(4), 247-251.

Osborne, J. W. (2010). Applying the Box-Cox transformation. Practical Assessment, Research, and Evaluation, 15(12), 1-9.

Pan American Health Organization [PAHO]. (1994). Dengue and dengue hemorrhagic fever in the Americas: Guidelines for prevention and control. Scientific Publication No. 548. Washington, D.C.: Pan American Health Organization.

Pan American Health Organization [PAHO]. (2014). Chikungunya. Retrieved from http://www.paho.org

Pham, H. V., Doan, H. T., Phan, T. T., \& Minh, N. N. (2011). Ecological factors associated with dengue fever in a central highlands province, Vietnam. BMC Infectious Diseases, 11(1), 172.

Ridderstaat, J. (2007). The Lago story: The compelling story of an oil company on the island of Aruba. Editorial Charuba.

Ridderstaat, J., Oduber, M., Croes, R., Nijkamp, P., \& Martens, P. (2014). Impacts of seasonal patterns of climate on recurrent fluctuations in tourism demand: Evidence from Aruba. Tourism Management, 41, 245-256.

Rossi, V., \& Walker, J. (2005). Assessing the economic impact and costs of flu pandemics originating in Asia. L-20 Project Paper.

Sabot, O., Cohen, J. M., Hsiang, M. S., Kahn, J. G., Basu, S., Tang, L., ..., \& Feachem, R. G. A. (2010). Costs and financial feasibility of malaria elimination. The Lancet, 376(9752), 1604-1615.

Schwartz, E., Weld, L. H., Wilder-Smith, A., von Sonnenburg, F., Keystone, J. S., Kain, K. C., ..., \& GeoSentinel Surveillance Network. (2008). Seasonality, annual trends, and characteristics of dengue among ill returned travelers, 1997-2006. Emerging Infectious Diseases, 14(7), 1081-1088.

Scott, D. J., Lemieux, C. J., \& Malone, L. (2011). Climate services to support sustainable tourism and adaptation to climate change. Climate Research, 47(1/2), 111-122.

Stienlauf, S., Segal, G., Sidi, Y., \& Schwartz, E. (2005). Epidemiology of travel-related hospitalization. Journal of Travel Medicine, 12(3), 136-141.

Suaya, J. A., Shepard, D. S., \& Beatty, M. E. (2007). Dengue: Burden of disease and costs of illness. Geneva: World Health Organization on behalf of the Special Programme for Research and Training in Tropical Diseases: Scientific Working Group: Report on Dengue (Vol. TDR/SWG/08).

Tabari, H., Somee, B. S., \& Zadeh, M. R. (2011). Testing for long-term trends in climatic variables in Iran. Atmospheric Research, 100(1), 132-140.

Thacker, N., Acevedo, S., \& Perrelli, R. (2012). Caribbean growth in an international perspective: The role of tourism and size. International Monetary Fund Working Paper WP/12/235.

Torres-Reyna, O. (2014). Panel data analysis fixed and random effects (using Stata 10.x). Data \& Statistical Services. Retrieved from http://www.princeton.edu/ otorres/

United Nations Environment Programme [UNEP]. (2005). Making tourism more sustainable: A guide for policy makers. UNEP \& UNWTO.

Vanegas, M., \& Croes, R. R. (2000). Evaluation of demand: US tourists to Aruba. Annals of Tourism Research, 27(4), 946-963.

Wichmann, O., Hongsiriwon, S., Bowonwatanuwong, C., Chotivanich, K., Sukthana, Y., \& Pukrittayakamee, S. (2004). Risk factors and clinical features associated with severe dengue infection in adults and children during the 2001 epidemic in Chonburi, Thailand. Tropical Medicine and International Health, 9(9), 1022-1029.

Wichmann, O., Muhlberger, N., \& Jelinek, T. (2003). Dengue-The underestimated risk in travellers. Dengue Bulletin, 27, 126-137.

Wilks, D. S. (1995). Statistical methods in the atmospheric sciences. New York, N.Y.: Academic Press.

Wongkoon, S. I., Jaroensutasinee, M. U., \& Jaroensutasinee, K. R. (2011). Climatic variability and dengue virus transmission in Chiang Rai, Thailand. Biomedica, 27, 5-13. 
World Health Organization [WHO]. (2010). International travel and health: Situation as on 1 January 2010. World Health Organization.

Yin, R. K. (2009). Case study research: Design and methods (4th ed.). Thousand Oaks, C.A.: Sage Publications, Inc..

Yoshikawa, M. J., \& Kusriastuti, R. (2013). Surge of dengue virus infection and chikungunya fever in Bali in 2010: The burden of mosquito-borne infectious diseases in a tourist destination. Tropical Medicine and Health, 41(2), 67-78.

Yu, G., Schwartz, Z., \& Walsh, J. E. (2010). Climate change and tourism seasonality. Journal of Tourism, 11(2).

Yue, S., \& Wang, C. (2004). The Mann-Kendall test modified by effective sample size to detect trend in serially correlated hydrological series. Water Resources Management, 18(3), 201-218. 